\title{
Myocardial Infarction: An Overview of STEMI and NSTEMI Physiopathology and Treatment
}

\author{
J. G. Kingma Jr \\ Department of Medicine, Faculty of Medicine, Université Laval, Québec, Canada \\ Email: john.kingma@fmed.ulaval.ca
}

How to cite this paper: Kingma Jr, J.G (2018) Myocardial Infarction: An Overview of STEMI and NSTEMI Physiopathology and Treatment. World Journal of Cardiovascular Diseases, 8, 498-517. https://doi.org/10.4236/wjcd.2018.811049

Received: October 12, 2018

Accepted: November 9, 2018

Published: November 12, 2018

Copyright $\odot 2018$ by author and Scientific Research Publishing Inc. This work is licensed under the Creative Commons Attribution International License (CC BY 4.0).

http://creativecommons.org/licenses/by/4.0/

(c) (i) Open Access

\begin{abstract}
Patients with myocardial infarction resulting from acute coronary syndrome are classified by electrocardiographic presentation: 1-acute ST-segment elevation myocardial infarction (STEMI) or 2-non-ST-segment elevation myocardial infarction (NSTEMI). Prompt reperfusion of an infarct-related artery by percutaneous coronary interventions provides some relief of symptoms; long-term prognosis appears to be worse in STEMI compared to NSTEMI patients but clinical findings remain controversial. Reduced myocardial perfusion to the infarct area, caused in part by microvascular obstruction, is a privileged target for diverse pharmacologic or non-pharmacologic interventions (or combinations thereof) to improve clinical outcomes. To date, benefits of both pharmacologic and non-pharmacologic strategies to either limit microvascular obstruction and myocardial injury or improve myocardial perfusion are inconsistent. This review focuses on the physiopathological aspects of myocardial infarction in relation to development of STEMI/NSTEMI and on potential cardioprotective strategies.
\end{abstract}

\section{Keywords}

Ischemia, Reperfusion, Infarction, Ischemia, No-Reflow, Microcirculation, Blood Flow, Ischemic Conditioning

\section{Introduction}

Myocardial ischemia that results from a perfusion-dependent imbalance between supply and demand leads to myocyte necrosis which develops progressively depending on different factors (organ, species, cardiac work, duration of ischemia, collateral blood flow, etc.) [1]. In patients with myocardial infarction, 30-day mortality rates are between 7.8 - 11.4 percent (data reported by the American Heart Association in 2015). Of these, 18 percent men and 23 percent 
women ( $>45$ years of age) succumb within a year of their initial infarction; mortality rates are worse in both sexes 5 years post-infarction and among survivors, an important cohort develop heart failure [2].

The Task Force for the Universal Definition of Myocardial Infarction, recently classified myocardial infarction to five different subtypes. Type 1 infarction occurs because of plaque rupture, ulceration or dissection, etc. in the presence of unstable atherosclerotic coronary artery disease (CAD) that comprises blood flow with resultant myocardial necrosis. Type 2 infarction is caused by a disequilibrium between oxygen supply and demand produced by factors other than unstable CAD (i.e. toxic effects of endogenous circulating compounds-catecholamines, endothelial dysfunction, etc.). Type 3 infarction involves patients with cardiac death resulting from symptoms associated with myocardial ischemia but for whom cardiac biomarker results are lacking. Type 4 ( $a$ and $b$ ) infarction is linked to percutaneous coronary intervention and stent thrombosis, respectively while Type 5 infarction is related to coronary artery bypass grafting [3]. Diagnosis and treatment of patients with the hope of improving clinical outcomes depend on precise classification of infarction [4] [5].

In this review, we examine clinical and experimental findings regarding the physiopathology of myocardial infarction. Scientific literature was searched using MEDLINE, PubMed and Google Scholar with the keywords myocardial infarction, ischemia, STEMI, non-STEMI, cardioprotection and various combinations thereof. Additionally, we consulted experimental findings from studies in this field emanating from our laboratory.

\section{ST Segment and Non-ST Segment Elevation Myocardial Infarction}

Acute coronary syndromes lead to myocyte injury and subsequent death. In the clinical setting, their classification is based electrocardiographic presentation; ST-segment elevation myocardial infarction (STEMI; $\geq 2 \mathrm{~mm}$ ST segment elevation and prominent $\mathrm{T}$ waves on the electrocardiogram) and non-ST-segment elevation myocardial infarction (NSTEMI; symptoms of acute coronary syndrome exemplified by ST-segment depression and $\mathrm{T}$ wave inversion on the electrocardiogram). Location of ST-segment changes often depends on the myocardial region affected by acute ischemia [6] [7].

STEMI is a life-threatening and time-sensitive emergency that results from complete thrombotic occlusion of the infarct-related artery [8]; these patients generally present with severe chest pain and large myocardial risk areas. Rapid access to coronary revascularization strategies are recommended and lowering door-to-balloon times remains a priority for these patients [9]. Short-term mortality risk is high in approximately 30 percent of patients with STEMI. In the remaining 70 percent of cases the risk of mortality is $>5$ percent [10]. Zahn et al. [11] reported significantly higher in-hospital mortality in STEMI compared to NSTEMI patients. Interestingly, mortality risk may be lower 2 years after hospi- 
tal discharge in older STEMI patients [12]. Gender-related differences regarding clinical outcomes in female patients with STEMI and NSTEMI are not well documented but mortality in females with total coronary occlusion may be less than in men [13].

Questions remain regarding involvement of single or multi-vessel disease in these patients since they are important considerations for coronary interventions. Presence of multi-vessel disease is an independent risk factor for adverse cardiac events [14]; gender and smoking are also important risk factors [15].

Patients with NSTEMI generally present with a more heterogeneous condition (i.e. reduced coronary artery blood flow without complete coronary occlusion, coronary artery spasm, coronary embolism, myocarditis, etc.) but have a higher long-term mortality risk due to prevalence of comorbidities and multi-vessel coronary artery disease [16]. Tuohinen et al. studied the relation between electrocardiogram changes and echocardiographic findings in NSTEMI patients [17]; they reported that T-wave inversions depended on anatomic distribution of myocardial ischemia and were associated with variations in systolic cardiac function. Conversely, ST-segment depression did not correlate with areas of wall motion abnormalities (on echocardiography) but was associated with global and regional alterations in diastolic function. Physiopathological mechanisms responsible for these observations require clarification; in animal studies, subendocardial ischemia produces LV diastolic dysfunction characterized by increased LV end-diastolic pressure and diminished LV chamber compliance [18] [19]. Causes of T-wave inversion in NSTEMI are likely multifactorial being associated with total occlusion of an infarct-related artery accompanied by transmural infarction [20]; patients with an existing infarct might be beyond the stage of ST-segment elevation and only present post-ischemic T-wave inversion [17] [21]. In STEMI patients, T-wave inversion is associated with complete restoration of coronary perfusion [22]. Clearly, long-term prognosis in NSTEMI compared to STEMI patients remains the subject of debate; for example, the Global Registry of Acute Coronary Events (GRACE) study reported lower post-discharge mortality in STEMI versus NSTEMI patients [23] whereas others report the opposite [24].

\section{Myocardial Infarction}

Infarction produces necrosis characterized by loss of myocardial structure and cell death; this is followed by tissue repair including formation of scar. Different categories of myocardial necrosis (coagulation, colliquative and coagulation myocytolysis) are described in human and experimental studies [25] [26] [27]. Coagulation necrosis, the most common form, is principally but not exclusively caused by marked reductions in coronary perfusion and is characterized by loss of myocardial contractile properties (due to intracellular acidosis). Colliquative myocytolysis (i.e. liquefaction necrosis) is portrayed by lysis of myocardial fibers ensuing from release of hydrolytic enzymes by inflammatory cells (i.e. leuko- 
cytes, neutrophils, etc.). Lesions comprise loss of contractile proteins, vacuolization, edema and nuclear changes including fragmentation. Coagulative myocytolysis results from the action of toxins such as nicotine and carbon monoxide; histopathological features resemble those produced by sympathetic nervous system stimulation and catecholamine release [28] [29] [30].

Infarcts are generally classified on the basis of size-microscopic (focal necrosis), small ( $<10 \%$ of LV), medium $(10 \%-30 \%$ of LV) or large ( $>30 \%$ of LV); however, they are also classified on the basis of location (anterior, lateral, inferior, etc.) [1]. In addition, within the pathologic context, "acute, healing or healed" infarction should be used; in acute infarction inflammatory cells are present. In healed infarcts (i.e. 5 - 6 weeks post-infarction), scar tissue is manifest while inflammatory cell infiltration is absent and electrocardiographic morphology remains in flux.

Acute ischemic injury is classed as being either reversible, where myocytes survive ischemic durations $<15$ minutes, or irreversible, with no capacity for myocyte recovery. Early restoration of blood flow to reversibly injured myocytes is key to complete recovery of cellular function with no discernable sequelae. On the other hand, irreversible myocyte injury (i.e. necrosis) produces marked cellular ultrastructural changes such as cell swelling, denaturation of intracellular proteins, membrane disruption, presence of contraction bands and mitochondrial calcification, etc. due to metabolic failure and rapid depletion of high-energy stores [31] [32] [33]. Other modes of cellular injury and death (i.e. apoptosis, autophagy, oncosis) also merit attention. Conditions that control transition from one status to the other are widely debated [34] [35].

Recently, Jennings suggested that "myocytes are irreversibly injured when they fail to survive after restoration of the environment to normal' [36]. Timing of cell injury and location across the myocardial wall are also important criteria; for the most part, potentially salvageable myocytes are localised in the mid-myocardial and epicardial layers. This observation led to the realization that ischemia-induced myocyte injury follows a transmural gradient across the ventricular wall following acute coronary occlusion [37] [38]. Earlier studies also hypothesized that distinct states of flow reduction and ischemic injury affect myocyte vulnerability to damage [39] [40]. These conditions are important as successful reperfusion therapy necessitates that rapid restoration of blood flow be achieved to impede development of a transmural infarct. It is important to remember that during ischemia significant damage also occurs at the level of the coronary microvasculature (i.e. coronary collateral vessels) that affects functional recovery of diverse cellular components of the myocardial architecture; thus, failure to restore adequate blood flow can be caused by microvascular dysfunction. In addition, while myocytes comprise more than eighty percent of ventricular mass, other cell types integral to cardiac function (i.e. intra- and extra-cardiac sympathetic/parasympathetic neurons) are negatively affected by ischemia; however, their injury threshold is not well established (cf. reference 
[41] for additional discussion). Cardiocytes and cardiac neurons conceivably share common survival pathways; however, this remains to be proven [42]. Neuron plasticity in the cardiac neuraxis might be critical for post-infarction recovery of cardiac function [43] [44]. Interestingly, viable nerves that course over an infarcted region tend to remain so since oxygen and energy needs can be fulfilled via blood from extracardiac sources [45].

Myocyte death produced by reperfusion rather than the preceding ischemia is also possible [46]; however, no clear consensus is available regarding its existence. Potential examples of reperfusion injury include myocardial and vascular stunning, no-reflow and reperfusion arrhythmias. In NSTEMI patients, reperfusion injury may result from tissue oedema [47] [48]. Heyndrickx et al. reported that reversibly injured myocardium contracted less efficiently after reperfusion of the infarct-related artery [49]. During coronary occlusion opening of coronary collateral vessels in conditioned myocardium is associated with a marked reduction of ST segment elevation during repeated coronary occlusions [50] [51] [52]. However, Tomai et al. [53] could not confirm these findings during coronary angioplasty in patients with STEMI. Inability to show a positive relation between myocardial tissue viability and improved microvascular blood flow post-ischemia may be due to the lack of sensitivity of currently employed techniques to measure spatial distribution of blood flow within the deeper myocardial layers. Animal studies to evaluate recruitment of coronary collateral circulation are sparse; however, one study of ischemic conditioning in rabbits documented a trend to improved microvascular blood flow [54].

\section{No-Reflow}

A crucial factor for survival in STEMI patients is the early restoration of blood flow to the infarct-related epicardial coronary artery; this can be accomplished with primary percutaneous coronary interventions (PCI), stenting and early thrombolysis, which are essential for limitation of myocardial necrosis and maintenance of LV function. No-reflow in the heart (it can also occur in other organs) is defined as an inability to restore blood flow to previously ischemic myocardium even after return of infarct-related epicardial coronary artery patency due to microvascular obstruction (cf. recent review by Kloner et al. [55]) [56] [57]. This dynamic process is produced by ultrastructural alterations of vascular endothelium, platelet aggregation, inflammation, embolization by atherosclerotic plaque and thrombotic debris, etc. [58] [59] [60]. In animal experiments (using Thioflavin S or carbon black injected at the end of the reperfusion period), no-reflow zones appear to be confined within the anatomic risk zone and to areas that display myocardial necrosis [56]. No-reflow does not cause myocyte death; however, it is associated with altered healing (i.e. thinner scar formation) and infarct expansion, which ultimately affect ventricular function. Limited perfusion (after restoration of infarct-related artery patency) within the anatomic risk zone ultimately reduces accessibility of inflammatory 
cells (i.e. macrophages, neutrophils, etc.) that are involved in removal of cellular debris and delivery of a multitude of endogenous factors that are required for post-ischemic remodeling of compromised myocardium [61] [62]. The absence of microvascular obstruction results in improved LV function and reduced mortality [63] [64]. In general, therapies that reduce infarct size also reduce no-reflow zone size; however, some interventions (i.e. oxygen radical scavengers) may benefit no-reflow independently of their effect on infarct size [65].

No-reflow has been reported in humans after reperfusion therapy for STEMI using different imaging techniques [60] [66] [67] [68] [69] [70]. This is important as the presence of no-reflow can jeopardize clinical outcomes independent of infarct size [66] [68] [69]. Major differences in physiopathology of no-reflow exist between animal and clinical studies. For the most part, animal studies use models of non-atherosclerotic coronary arteries; however, in patients angioplasty or stent deployment within a ruptured atherosclerotic plaque produces debris (i.e. microemboli) that result in downstream vascular obstruction over and above that produced by endothelial swelling and disruption [71]. Interventions such as mechanical thrombectomy (i.e. during catheterization), pharmacology (i.e. calcium channel blockers, adenosine, platelet aggregation blockers, anti-thrombotics, etc.) and manual aspiration of thrombus all appear to affect myocardial perfusion and clinical outcomes [72] [73] [74].

Pathogenesis of microvascular obstruction (MVO) between STEMI and NSTEMI patients may not be the same. Prevalence of MVO is markedly lower in NSTEMI compared to STEMI patients [75] [76]. Some evidence suggests that infarcts are smaller in NSTEMI patients. Reasons for the observed differences are unclear; however, an independent association between extension of MVO and infarct size exists [47] [77] [78]. Culprit vessel involvement (i.e. for ischemia) might also be an independent predictor of MVO; Guerra et al. [75] showed that the left circumflex artery was more frequently implicated in NSTEMI (versus STEMI [79]); considered as additional proof for the existence of transmural myocardial necrosis despite minimal presence of electrocardiographic criteria.

A recent meta-analysis (i.e. comprising seven randomized clinical trials) report from de Waha et al. examined the relation between MVO within the first 7 days of reperfusion and subsequent all-cause mortality, hospitalization for heart failure and re-infarction within a year follow-up in patients with STEMI [80]. They showed that MVO was independently predictive of all-cause mortality even after adjustment for infarct size; however, MVO could not independently predict re-infarction after PCI in STEMI patients. Baseline determinants of MVO such as TIMI (thrombolysis in myocardial infarction) flow, symptom-to-device time, infarct location, etc. correlated strongly with mortality. Physiopathological mechanisms for adverse impact of MVO on clinical outcomes are multifaceted and include post-infarction remodeling, inflammation, ventricular healing, etc. In animal studies, MVO is associated with increased myocardial stiffness and reduced elasticity; over time, these factors are allied with increases in wall stress 
and wall thickening [81] [82]. On the other hand, absence of MVO results in marked improvement of LV ejection fraction over time [63] [64] [82]. Based on these findings, it would be reasonable to hypothesize that interventions that limit MVO potentially ameliorate clinical outcomes.

\section{Protection Strategies-Non-Pharmacologic}

Application of multiple, brief cycles of nonlethal ischemia and reperfusion prior to a prolonged ischemic event significantly delays progression of cell death [83]; ischemic conditioning performed before, during or after acute ischemia has been evaluated in a host of animal species but protection only occurs when reperfusion is present [84]. Cellular protection is documented in most species; however, results in humans are variable [85] [86]. Proof-of-concept clinical studies using remote ischemic conditioning (i.e. transient cycles of ischemia/reperfusion in a distal organ) have shown considerable potential to limit organ injury [87] [88] [89] [90]. In STEMI patients, remote ischemic preconditioning diminishes troponin I release ( $24 \mathrm{~h}$ post-PCI), chest pain and ST-segment deviation on the electrocardiogram [91] [92] [93]. Remote ischemic conditioning also improves endothelial function in patients with acute myocardial infarction when applied prior to primary PCI [94]; other studies put forward that this intervention leads to persistent protection and potential reduction of long-term clinical events [95] [96] [97]. McLeod et al. recently completed a meta-analysis of randomized controlled clinical trials (over 1200 patients enrolled) that compared PCI with, and without, remote ischemic conditioning in STEMI patients; they determined that remote ischemic conditioning was a promising adjunctive treatment for prevention of reperfusion injury [98]. Interestingly, maximum benefit from remote conditioning occurs in patients with the greatest degree of cardiac ischemia (i.e. TIMI; 0 - 1 flow) [99]. The CONDI2/ERIC-PPCI trial, a randomized controlled clinical study, is currently ongoing to evaluate whether remote ischemic conditioning can reduce cardiac death and hospitalization for heart failure at 12 months in patients presenting with a ST-elevation myocardial infarction and treated by percutaneous coronary intervention [85]. While remote conditioning is a promising adjunctive treatment to PCI to limit reperfusion injury, further studies in different patient cohorts are necessary to secure its status as a legitimate cardioprotective therapy. Innate ischemic preconditioning could occur within the context of pre-infarction angina and exercise-induced ischemia. Pre-infarction angina mitigates ischemic injury by triggering endogenous intracellular signalling pathways [100]; exercise ischemia (i.e. warm-up angina) is reported to occur consequent to an increase in metabolic efficiency and not by improvements in myocardial perfusion [93] [101].

\section{Protection Strategies-Pharmacologic}

Pharmacologic interventions administered at the time of PCI also improve clinical outcomes in STEMI patients. Recently, Bullock et al. reported significant 
improvement of clinical outcomes in STEMI patients given intracoronary adenosine as an adjunct to reperfusion [102]; these findings contrast with earlier meta-analyses of randomized control clinical trials, which failed to document clinical benefit in patients with STEMI [103] [104]. Benefits of intracoronary adenosine treatment were associated with improved myocardial perfusion; interestingly, administration via the intravenous route provided no positive effects (cf. AMISTAD-II study) [105] [106]. Adenosine is a potent vasodilator with anti-inflammatory properties that contribute to reduce microvascular obstruction (due to neutrophil adhesion and migration, antiplatelet effects, etc.) and diminish risk of adverse cardiac remodeling [107] [108] [109]. In experimental studies, adenosine (dose-dependent) limits ischemic injury; however, questions remain regarding efficacy with adenosine administration at the time of reperfusion [108] [110]. In humans, the REFLO-STEMI trial examined effects of intracoronary adenosine (and other vasodilators) on infarct size and microvascular obstruction [111] [112]; results indicate that adenosine did not limit infarct size or reperfusion injury when administered during PCI but may (at higher dosages) cause cardiac toxicity with worse clinical outcomes. In a recent study from Zhou and co-workers, combination therapy (atorvastatin, IC adenosine, tirofiban, thrombus aspiration) in addition to PCI had a markedly lower incidence of no-reflow and improved prognosis in STEMI patients with a high risk of no-reflow [113]. Several pre-clinical and clinical studies have examined combined therapy approaches with inconsistent results [99] [114] [115]; further investigation using combined reperfusion therapy and pharmacologic compounds that target pro-survival pathways is necessary.

Pharmacologic compounds currently focused on protecting against post-ischemic vascular injury and no-reflow in STEMI patients include statins, ß-blockers, cyclosporine, nicorandil ( $\mathrm{K}_{\mathrm{ATP}}$ channel agonist), exenatide and liraglutide (GLP-1 analogues) [116]-[122]. Non-steroidal anti-inflammatory drugs have also been studied but their efficacy in STEMI and NSTEMI patients is inconsistent [123] [124] [125]. The relation between platelet activation/aggregation and major adverse cardiovascular events in STEMI and NSTEMI patients has also been investigated in numerous clinical trials (DISPERSE, PLATO, APELOT, ONSET/OFFSET, etc.) [126] [127] [128]. Use of P2Y12 antagonists such as prasugrel, clopidogrel, ticagrelor, etc. have been studied; benefit-to-risk ratio balance with these drugs remains a concern because of an increased risk of ischemic complications [129] [130] [131].

\section{Summary}

Understanding the physiopathological mechanisms associated with development of myocardial injury after acute coronary artery occlusion is imperative for elaboration of effective therapeutic interventions (pharmacologic, non-pharmacologic, combination therapy) to improve clinical outcomes in STEMI and NSTEMI patients. The ability to specifically target reperfusion injury in acute coronary syndrome patients 
could enhance capacity to reduce the adverse consequences of myocardial infarction. More information is needed regarding pathogenesis of cardiac injury in patients with comorbidities, co-medications along with age and gender differences.

\section{Conflicts of Interest}

The author declares no conflicts of interest regarding the publication of this paper.

\section{References}

[1] Alpert, J.S., Thygesen, K., Antman, E. and Bassand, J.P. (2000) Myocardial Infarction Redefined-A Consensus Document of The Joint European Society of Cardiology/American College of Cardiology Committee for the Redefinition of Myocardial Infarction. Journal of the American College of Cardiology, 36, 959-969. https://doi.org/10.1016/S0735-1097(00)00804-4

[2] Mozaffarian, D., Benjamin, E.J., Go, A.S., Arnett, D.K., Blaha, M.J., Cushman, M., de Ferranti, S., Despres, J.P., Fullerton, H.J., Howard, V.J., et al. (2015) Heart Disease and Stroke Statistics-2015 Update: A Report from the American Heart Association. Circulation, 131, e29-322. https://10.1161/CIR.0000000000000152

[3] Thygesen, K., Alpert, J.S., Jaffe, A.S., Simoons, M.L., Chaitman, B.R., White, H.D. and The Writing Group on Behalf of the Joint ESC/ACCF/AHA/WHF Task Force for the Universal Definition of Myocardial Infarction (2012) Third Universal Definition of Myocardial Infarction. Journal of the American College of Cardiology, 60, 1581-1598. https://doi.org/10.1016/j.jacc.2012.08.001

[4] Mihatov, N., Januzzi Jr., J.L. and Gaggin, H.K. (2017) Type 2 Myocardial Infarction due to Supply-Demand Mismatch. Trends in Cardiovascular Medicine, 27, 408-417. https://doi.org/10.1016/j.tcm.2017.03.002

[5] Smilowitz, N.R., Weiss, M.C., Mauricio, R., Mahajan, A.M., Dugan, K.E., Devanabanda, A., Pulgarin, C., Gianos, E., Shah, B., Sedlis, S.P., et al. (2016) Provoking Conditions, Management and Outcomes of Type 2 Myocardial Infarction and Myocardial Necrosis. International Journal of Cardiology, 218, 196-201.

https://doi.org/10.1016/j.ijcard.2016.05.045

[6] Gregg, R.E. and Babaeizadeh, S. (2014) Detection of Culprit Coronary Lesion Location in Pre-Hospital 12-Lead ECG. Journal of Electrocardiology, 47, 890-894. https://doi.org/10.1016/j.jelectrocard.2014.07.014

[7] Ishida, M., Kato, S. and Sakuma, H. (2009) Cardiac MRI in Ischemic Heart Disease. Circulation Journal, 73, 1577-1588. https://doi.org/10.1253/circj.CJ-09-0524

[8] Manari, A., Albiero, R. and De Servi, S. (2009) High-Risk Non-ST-Segment Elevation Myocardial Infarction versus ST-Segment Elevation Myocardial Infarction: Same Behaviour and Outcome? Journal of Cardiovascular Medicine (Hagerstown), 10, S13-S16. https://doi.org/10.2459/01.JCM.0000362039.48638.92

[9] Brodie, B.R., Hansen, C., Stuckey, T.D., Richter, S., Versteeg, D.S., Gupta, N., Downey, W.E. and Pulsipher, M. (2006) Door-to-Balloon Time with Primary Percutaneous Coronary Intervention for Acute Myocardial Infarction Impacts Late Cardiac Mortality in High-Risk Patients and Patients Presenting Early after the Onset of Symptoms. Journal of the American College of Cardiology, 47, 289-295. https://doi.org/10.1016/j.jacc.2005.08.065

[10] Kent, D.M., Schmid, C.H., Lau, J. and Selker, H.P. (2002) Is Primary Angioplasty for Some as Good as Primary Angioplasty for All? Journal of General Internal Med- 
icine, 17, 887-894. https://doi.org/10.1046/j.1525-1497.2002.11232.x

[11] Zahn, R., Schweppe, F., Zeymer, U., Schiele, R., Gitt, A.K., Mark, B., Frilling, B., Seidl, K., Winkler, R., Heer, T., et al. (2009) Reperfusion Therapy for Acute ST-Elevation and Non ST-Elevation Myocardial Infarction: What Can Be Achieved in Daily Clinical Practice in Unselected Patients at an Interventional Center? Acute Card Care, 11, 92-98. https://doi.org/10.1080/17482940902806106

[12] Vora, A.N., Wang, T.Y., Hellkamp, A.S., Thomas, L., Henry, T.D., Goyal, A. and Roe, M.T. (2016) Differences in Short- and Long-Term Outcomes Among Older Patients with ST-Elevation versus Non-ST-Elevation Myocardial Infarction with Angiographically Proven Coronary Artery Disease. Circulation: Cardiovascular Quality and Outcomes, 9, 513-522. https://doi.org/10.1161/CIRCOUTCOMES.115.002312

[13] Tajstra, M., Hawranek, M., Desperak, P., Cislak, A. and Gasior, M. (2017) Gap in Gender Parity: Gender Disparities in Incidence and Clinical Impact of Chronic Total Occlusion in Non-Infarct Artery in Patients with Non-ST-Segment Elevation Myocardial Infarction and Multivessel Coronary Artery Disease. Oncotarget, 8, 79137-79146. https://doi.org/10.18632/oncotarget.16134

[14] Luyckx, E., Everaert, B.R., Van der Veken, B., Van Leuven, W., Timmermans, J.P., Vrints, C.J., De Meyer, G.R.Y., Martinet, W. and Dewilde, S. (2018) Cytoprotective Effects of Transgenic Neuroglobin Overexpression in an Acute and Chronic Mouse Model of Ischemic Heart Disease. Heart Vessels, 33, 80-88. https://doi.org/10.1007/s00380-017-1065-5

[15] Ferrara, L.A., Russo, B.F., Gente, R., Esposito, G., Rapacciuolo, A. and de Simone, G. (2013) STEMI and NSTEMI: A Mono versus a Multivessel Disease? International Journal of Cardiology, 168, 2905-2906. https://doi.org/10.1016/j.ijcard.2013.03.154

[16] Chan, M.Y., Sun, J.L., Newby, L.K., Shaw, L.K., Lin, M., Peterson, E.D., Califf, R.M., Kong, D.F. and Roe, M.T. (2009) Long-Term Mortality of Patients Undergoing Cardiac Catheterization for ST-Elevation and Non-ST-Elevation Myocardial Infarction. Circulation, 119, 3110-3117. https://doi.org/10.1161/CIRCULATIONAHA.108.799981

[17] Tuohinen, S.S., Rankinen, J., Skytta, T., Huhtala, H., Virtanen, V., Kellokumpu-Lehtinen, P.L., Raatikainen, P. and Nikus, K. (2018) Associations between ECG Changes and Echocardiographic Findings in Patients with Acute Non-ST Elevation Myocardial Infarction. Journal of Electrocardiology, 51, 188-194. https://doi.org/10.1016/j.jelectrocard.2017.11.007

[18] Guyton, R.A., McClenathan, J.H., Newman, G.E. and Michaelis, L.L. (1977) Significance of Subendocardial S-T Segment Elevation Caused by Coronary Stenosis in the Dog. American Journal of Cardiology, 40, 373-381. https://doi.org/10.1016/0002-9149(77)90159-X

[19] Palacios, I., Johnson, R.A., Newell, J.B. and Powell, W.J. (1976) Left Ventricular End-Diastolic Pressure Volume Relationships with Experimental Acute Global Ischemia. Circulation, 53, 428-436. https://doi.org/10.1161/01.CIR.53.3.428

[20] Sarafoff, N., Schuster, T., Vochem, R., Fichtner, S., Martinoff, S., Schwaiger, M., Schomig, A. and Ibrahim, T. (2013) Association of ST-Elevation and Non-ST-Elevation Presentation on ECG with Transmurality and Size of Myocardial Infarction as Assessed by Contrast-Enhanced Magnetic Resonance Imaging. Journal of Electrocardiology, 46, 100-106. https://doi.org/10.1016/j.jelectrocard.2012.12.017

[21] Nikus, K., Pahlm, O., Wagner, G., Birnbaum, Y., Cinca, J., Clemmensen, P., Eskola, M., Fiol, M., Goldwasser, D., Gorgels, A., et al. (2010) Electrocardiographic Classi- 
fication of Acute Coronary Syndromes: A Review by a Committee of the International Society for Holter and Non-Invasive Electrocardiology. Journal of Electrocardiology, 43, 91-103. https://doi.org/10.1016/j.jelectrocard.2009.07.009

[22] Doevendans, P.A., Gorgels, A.P., van der Zee, R., Partouns, J., Bar, F.W. and Wellens, H.J. (1995) Electrocardiographic Diagnosis of Reperfusion during Thrombolytic Therapy in Acute Myocardial Infarction. American Journal of Cardiology, 75, 1206-1210. https://doi.org/10.1016/S0002-9149(99)80763-2

[23] Goldberg, R.J., Currie, K., White, K., Brieger, D., Steg, P.G., Goodman, S.G., Dabbous, O., Fox, K.A. and Gore, J.M. (2004) Six-Month Outcomes in a Multinational Registry of Patients Hospitalized with an Acute Coronary Syndrome (the Global Registry of Acute Coronary Events [GRACE]). American Journal of Cardiology, 93, 288-293. https://doi.org/10.1016/j.amjcard.2003.10.006

[24] Polonski, L., Gasior, M., Gierlotka, M., Osadnik, T., Kalarus, Z., Trusz-Gluza, M., Zembala, M., Wilczek, K., Lekston, A., Zdrojewski, T., et al. (2011) A Comparison of ST Elevation versus Non-ST Elevation Myocardial Infarction Outcomes in a Large Registry Database: Are Non-ST Myocardial Infarctions Associated with Worse Long-Term Prognoses? International Journal of Cardiology, 152, 70-77. https://doi.org/10.1016/j.ijcard.2010.07.008

[25] Leone, A. (2017) Myocardial Infarction. Pathological Relevance and Relationship with Coronary Risk Factors. Current Pharmaceutical Design, 23, 3205-3216. https://doi.org/10.2174/1381612823666170317123426

[26] Katz, A.M. (1971) Effects of Ischemia on the Cardiac Contractile Proteins. Cardiology, 56, 276-283. https://doi.org/10.1159/000169371

[27] Cantin, M. and Leone, A. (1981) Morphology of Myocardial Infarction. Methods and Achievements in Experimental Pathology, 10, 244-284.

[28] Baroldi, G. (1974) Letter: Myocardial Necrosis: The Need for Definition. Journal of Molecular and Cellular Cardiology, 6, 401-402.

https://doi.org/10.1016/0022-2828(74)90081-9

[29] Baroldi, G., Radice, F., Schmid, G. and Leone, A. (1974) Morphology of Acute Myocardial Infarction in Relation to Coronary Thrombosis. American Heart Journal, 87, 65-75. https://doi.org/10.1016/0002-8703(74)90392-5

[30] Csapo, Z., Dusek, J. and Rona, G. (1972) Early Alterations of the Cardiac Muscle Cells in Isoproterenol-Induced Necrosis. Archives of Pathology, 93, 356-365.

[31] Leist, M., Single, B., Castoldi, A.F., Kuhnle, S. and Nicotera, P. (1997) Intracellular Adenosine Triphosphate (ATP) Concentration: A Switch in the Decision between Apoptosis and Necrosis. The Journal of Experimental Medicine, 185, 1481-1486. https://doi.org/10.1084/jem.185.8.1481

[32] Jennings, R.B., Reimer, K.A., Hill, M.L. and Mayer, S.E. (1981) Total Ischemia in Dog Hearts in Vitro: 1. Comparison of High Energy Phosphate Production, Utilization and Depletion and of Adenosine Nucleotide Catabolism in Total Ischemia Versus Severe Ischemia in Vivo. Circulation Research, 49, 892-900. https://doi.org/10.1161/01.RES.49.4.892

[33] Reimer, K.A., Jennings, R.B. and Hill, M.L. (1981) Total Ischemia in Dog Hearts in Vitro: 2. High Energy Phosphate Depletion and Associated Defects in Energy Metabolism, Cell Volume Regulation and Sarcolemmal Integrity. Circulation Research, 49, 901-911. https://doi.org/10.1161/01.RES.49.4.901

[34] Xia, P., Liu, Y. and Cheng, Z. (2016) Signaling Pathways in Cardiac Myocyte Apoptosis. BioMed Research International, 2016, Article ID: 9583268.

https://doi.org/10.1155/2016/9583268 
[35] Hotchkiss, R.S., Strasser, A., McDunn, J.E. and Swanson, P.E. (2009) Cell Death. The New England Journal of Medicine, 361, 1570-1583. https://doi.org/10.1056/NEJMra0901217

[36] Jennings, R.B. (2013) Historical Perspective on the Pathology of Myocardial Ischemia/Reperfusion Injury. Circulation Research, 113, 428-438. https://doi.org/10.1161/CIRCRESAHA.113.300987

[37] Reimer, K.A., Lowe, J.E., Rasmussen, M.M. and Jennings, R.B. (1977) The Wavefront Phenomenon of Ischemic Cell Death: I. Myocardial Infarct Size vs. Duration of Coronary Occlusion in Dogs. Circulation, 56, 786-794. https://doi.org/10.1161/01.CIR.56.5.786

[38] Reimer, K.A. and Jennings, R.B. (1979) The "Wavefront Phenomenon" of Myocardial Ischemic Cell Death. II. Transmural Progression of Necrosis within the Framework of Ischemic Bed Size (Myocardium at Risk) and Collateral Flow. Laboratory Investigation, 40, 633-644.

[39] Yellon, D.M., Hearse, D.J., Crome, R. and Wyse, R.K.H. (Laboratory Investigation) (1983) Temporal and Spatial Characteristics of Evolving Cell Injury during Regional Myocardial Ischemia in the Dog: The "Border Zone" Controversy. Journal of the American College of Cardiology, 2, 661-670. https://doi.org/10.1016/S0735-1097(83)80306-4

[40] Hearse, D.J., Crome, R., Yellon, D.M. and Wyse, R. (1983) Metabolic and Flow Correlates of Myocardial Ischaemia. Cardiovascular Research, 17, 452-458. https://doi.org/10.1093/cvr/17.8.452

[41] Kingma, J.G., Simard, D. and Rouleau, J.R. (2017) Influence of Cardiac Nerve Status on Cardiovascular Regulation and Cardioprotection. World Journal of Cardiology, 9, 508-520. https://doi.org/10.4330/wjc.v9.i6.508

[42] Gourine, A. and Gourine, A.V. (2014) Neural Mechanisms of Cardioprotection. Physiology (Bethesda), 29, 133-140. https://doi.org/10.1152/physiol.00037.2013

[43] Fukuda, K., Kanazawa, H., Aizawa, Y., Ardell, J.L. and Shivkumar, K. (2015) Cardiac Innervation and Sudden Cardiac Death. Circulation Research, 116, 2005-2019. https://doi.org/10.1161/CIRCRESAHA.116.304679

[44] Hardwick, J.C., Ryan, S.E., Beaumont, E., Ardell, J.L. and Southerland, E.M. (2014) Dynamic Remodeling of the Guinea Pig Intrinsic Cardiac Plexus Induced by Chronic Myocardial Infarction. Autonomic Neuroscience, 181, 4-12. https://doi.org/10.1016/j.autneu.2013.10.008

[45] Janes, R.D., Johnstone, D.E. and Armour, J.A. (1987) Functional Integrity of Intrinsic Cardiac Nerves Located over an Acute Transmural Myocardial Infarction. Canadian Journal of Physiology and Pharmacology, 65, 64-69.

https://doi.org/10.1139/y87-012

[46] Hausenloy, D.J. and Yellon, D.M. (2013) Myocardial Ischemia-Reperfusion Injury: A Neglected Therapeutic Target. Journal of Clinical Investigation, 123, 92-100. https://doi.org/10.1172/JCI62874

[47] Mewton, N., Bonnefoy, E., Revel, D., Ovize, M., Kirkorian, G. and Croisille, P. (2009) Presence and Extent of Cardiac Magnetic Resonance Microvascular Obstruction in Reperfused Non-ST-Elevated Myocardial Infarction and Correlation with Infarct Size and Myocardial Enzyme Release. Cardiology, 113, 50-58. https://doi.org/10.1159/000167042

[48] Migliore, F., Zorzi, A., Marra, M.P., Basso, C., Corbetti, F., De Lazzari, M., Tarantini, G., Buja, P., Lacognata, C., Thiene, G., et al. (2011) Myocardial Edema Underlies 
Dynamic T-Wave Inversion (Wellens' ECG Pattern) in Patients with Reversible Left Ventricular Dysfunction. Heart Rhythm, 8, 1629-1634.

https://doi.org/10.1016/j.hrthm.2011.04.035

[49] Heyndrickx, G.R., Millard, R.W., McRitchie, R.J., Maroko, P.R. and Vatner, S.F. (1975) Regional Myocardial Functional and Electrophysiological Alterations after Brief Coronary Artery Occlusion in Conscious Dogs. Journal of Clinical Investigation, 56, 978-985. https://doi.org/10.1172/JCI108178

[50] Sakata, Y., Kodama, K., Kitakaze, M., Masuyama, T., Hirayama, A., Lim, Y.J., Ishikura, F., Sakai, A., Adachi, T. and Hori, M. (1997) Different Mechanisms of Ischemic Adaptation to Repeated Coronary Occlusion in Patients with and without Recruitable Collateral Circulation. Journal of the American College of Cardiology, 30, 1679-1686. https://doi.org/10.1016/S0735-1097(97)00377-X

[51] Rentrop, K.P., Cohen, M., Blanke, H. and Phillips, R.A. (1985) Changes in Collateral Channel Filling Immediately after Controlled Coronary Artery Occlusion by an Angioplasty Balloon in Human Subjects. Journal of the American College of Cardiology, 5, 587-592. https://doi.org/10.1016/S0735-1097(85)80380-6

[52] Billinger, M., Fleisch, M., Eberli, F.R., Garachemani, A., Meier, B. and Seiler, C. (1999) Is the Development of Myocardial Tolerance to Repeated Ischemia in $\mathrm{Hu}-$ mans Due to Preconditioning or to Collateral Recruitment? Journal of the American College of Cardiology, 33, 1027-1035. https://doi.org/10.1016/S0735-1097(98)00674-3

[53] Tomai, F., Crea, F., Gaspardone, A., Versaci, F., Ghini, A.S., Ferri, C., Desideri, G., Chiariello, L. and Gioffre, P.A. (1999) Effects of Naloxone on Myocardial Ischemic Preconditioning in Humans. Journal of the American College of Cardiology, 33, 1863-1869. https://doi.org/10.1016/S0735-1097(99)00095-9

[54] Hale, S.L. and Kloner, R.A. (1999) Ischemic Preconditioning and Myocardial Hypothermia in Rabbits with Prolonged Coronary Artery Occlusion. American Journal of Physiology, 276, H2029-H2034.

[55] Kloner, R.A., King, K.S. and Harrington, M. (2018) No-Reflow Phenomenon in Heart and Brain. American Journal of Physiology-Heart and Circulatory Physiolo$g y$, 315, H550-H562. https://doi.org/10.1152/ajpheart.00183.2018

[56] Kloner, R.A., Ganote, C.E. and Jennings, R.B. (1974) The "No-Reflow" Phenomenon after Temporary Coronary Occlusion in the Dog. Journal of Clinical Investigation, 54, 1496-1508. https://doi.org/10.1172/JCI107898

[57] Reffelmann, T. and Kloner, R.A. (2006) The No-Reflow Phenomenon: A Basic Mechanism of Myocardial Ischemia and Reperfusion. Basic Research in Cardiology, 101, 359-372. https://doi.org/10.1007/s00395-006-0615-2

[58] Skyschally, A., Leineweber, K., Gres, P., Haude, M., Erbel, R. and Heusch, G. (2006) Coronary Microembolization. Basic Research in Cardiology, 101, 373-382.

https://doi.org/10.1007/s00395-006-0616-1

[59] Skyschally, A., Schulz, R., Erbel, R. and Heusch, G. (2002) Reduced Coronary and Inotropic Reserves with Coronary Microembolization. American Journal of Physiology-Heart and Circulatory Physiology, 282, H611-H614. https://doi.org/10.1152/ajpheart.00797.2001

[60] Kloner, R.A. (2011) No-Reflow Phenomenon: Maintaining Vascular Integrity. Journal of Cardiovascular Pharmacology and Therapeutics, 16, 244-250. https://doi.org/10.1177/1074248411405990

[61] Wu, K.C. (2012) CMR of Microvascular Obstruction and Hemorrhage in Myocardial Infarction. Journal of Cardiovascular Magnetic Resonance, 14, 68. 
https://doi.org/10.1186/1532-429X-14-68

[62] Sutton, M.G. and Sharpe, N. (2000) Left Ventricular Remodeling after Myocardial Infarction: Pathophysiology and Therapy. Circulation, 101, 2981-2988.

https://doi.org/10.1161/01.CIR.101.25.2981

[63] Nijveldt, R., Beek, A.M., Hirsch, A., Stoel, M.G., Hofman, M.B., Umans, V.A., Algra, P.R., Twisk, J.W. and van Rossum, A.C. (2008) Functional Recovery after Acute Myocardial Infarction: Comparison between Angiography, Electrocardiography, and Cardiovascular Magnetic Resonance Measures of Microvascular Injury. Journal of the American College of Cardiology, 52, 181-189.

https://doi.org/10.1016/j.jacc.2008.04.006

[64] Orn, S., Manhenke, C., Greve, O.J., Larsen, A.I., Bonarjee, V.V., Edvardsen, T. and Dickstein, K. (2009) Microvascular Obstruction Is a Major Determinant of Infarct Healing and Subsequent Left Ventricular Remodelling Following Primary Percutaneous Coronary Intervention. European Heart Journal, 30, 1978-1985.

https://doi.org/10.1093/eurheartj/ehp219

[65] Przyklenk, K. and Kloner, R.A. (1989) Reperfusion Injury by Oxygen-Derived Free Radicals? Effect of Superoxide Dismutase plus Catalase, Given at the Time of Reperfusion, on Myocardial Infarct Size, Contractile Function, Coronary Microvasculature, and Regional Myocardial Blood Flow. Circulation Research, 64, 86-96. https://doi.org/10.1161/01.RES.64.1.86

[66] Wu, K.C., Zerhouni, E.A., Judd, R.M., Lugo-Olivieri, C.H., Barouch, L.A., Schulman, S.P., Blumenthal, R.S. and Lima, J.A. (1998) Prognostic Significance of Microvascular Obstruction by Magnetic Resonance Imaging in Patients with Acute Myocardial Infarction. Circulation, 97, 765-772. https://doi.org/10.1161/01.CIR.97.8.765

[67] Kim, R.J., Chen, E.L., Lima, J.A. and Judd, R.M. (1996) Myocardial Gd-DTPA Kinetics Determine MRI Contrast Enhancement and Reflect the Extent and Severity of Myocardial Injury after Acute Reperfused Infarction. Circulation, 94, 3318-3326. https://doi.org/10.1161/01.CIR.94.12.3318

[68] Niccoli, G., Burzotta, F., Galiuto, L. and Crea, F. (2009) Myocardial No-Reflow in Humans. Journal of the American College of Cardiology, 54, 281-292. https://doi.org/10.1016/j.jacc.2009.03.054

[69] Bolognese, L., Carrabba, N., Parodi, G., Santoro, G.M., Buonamici, P., Cerisano, G. and Antoniucci, D. (2004) Impact of Microvascular Dysfunction on Left Ventricular Remodeling and Long-Term Clinical Outcome after Primary Coronary Angioplasty for Acute Myocardial Infarction. Circulation, 109, 1121-1126. https://doi.org/10.1161/01.CIR.0000118496.44135.A7

[70] Galiuto, L., Garramone, B., Scara, A., Rebuzzi, A.G., Crea, F., La Torre, G., Funaro, S., Madonna, M., Fedele, F., Agati, L. and Investigators, A. (2008) The Extent of Microvascular Damage during Myocardial Contrast Echocardiography Is Superior to Other Known Indexes of Post-Infarct Reperfusion in Predicting Left Ventricular Remodeling: Results of the Multicenter AMICI Study. Journal of the American College of Cardiology, 51, 552-559. https://doi.org/10.1016/j.jacc.2007.09.051

[71] Heusch, G., Kleinbongard, P., Bose, D., Levkau, B., Haude, M., Schulz, R. and Erbel, R. (2009) Coronary Microembolization: From Bedside to Bench and Back to Bedside. Circulation, 120, 1822-1836. https://doi.org/10.1161/CIRCULATIONAHA.109.888784

[72] Svilaas, T., Vlaar, P.J., van der Horst, I.C., Diercks, G.F., de Smet, B.J., van den Heuvel, A.F., Anthonio, R.L., Jessurun, G.A., Tan, E.S., Suurmeijer, A.J. and Zijlstra, 
F. (2008) Thrombus Aspiration during Primary Percutaneous Coronary Intervention. The New England Journal of Medicine, 358, 557-567. https://doi.org/10.1056/NEJMoa0706416

[73] Jaffe, R., Dick, A. and Strauss, B.H. (2010) Prevention and Treatment of Microvascular Obstruction-Related Myocardial Injury and Coronary No-Reflow Following Percutaneous Coronary Intervention: A Systematic Approach. JACC: Cardiovascular Interventions, 3, 695-704. https://doi.org/10.1016/j.jcin.2010.05.004

[74] Micari, A., Belcik, T.A., Balcells, E.A., Powers, E., Wei, K., Kaul, S. and Lindner, J.R. (2005) Improvement in Microvascular Reflow and Reduction of Infarct Size with Adenosine in Patients Undergoing Primary Coronary Stenting. American Journal of Cardiology, 96, 1410-1415. https://doi.org/10.1016/j.amjcard.2005.06.090

[75] Guerra, E., Hadamitzky, M., Ndrepepa, G., Bauer, C., Ibrahim, T., Ott, I., Laugwitz, K.L., Schunkert, H. and Kastrati, A. (2014) Microvascular Obstruction in Patients with Non-ST-Elevation Myocardial Infarction: A Contrast-Enhanced Cardiac Magnetic Resonance Study. The International Journal of Cardiovascular Imaging, 30, 1087-1095. https://doi.org/10.1007/s10554-014-0430-Z

[76] Hombach, V., Merkle, N., Kestler, H.A., Torzewski, J., Kochs, M., Marx, N., Nusser, T., Burgstahler, C., Rasche, V., Bernhardt, P., et al. (2008) Characterization of Patients with Acute Chest Pain Using Cardiac Magnetic Resonance Imaging. Clinical Research in Cardiology, 97, 760-767. https://doi.org/10.1007/s00392-008-0675-4

[77] Husser, O., Bodi, V., Sanchis, J., Nunez, J., Lopez-Lereu, M.P., Monmeneu, J.V., Gomez, C., Rumiz, E., Merlos, P., Bonanad, C., et al. (2013) Predictors of Cardiovascular Magnetic Resonance-Derived Microvascular Obstruction on Patient Admission in STEMI. International Journal of Cardiology, 166, 77-84. https://doi.org/10.1016/j.ijcard.2011.09.083

[78] Tzivoni, D., Koukoui, D., Guetta, V., Novack, L., Cowing, G. and Investigators, C.S. (2008) Comparison of Troponin T to Creatine Kinase and to Radionuclide Cardiac Imaging Infarct Size in Patients with ST-Elevation Myocardial Infarction Undergoing Primary Angioplasty. American Journal of Cardiology, 101, 753-757. https://doi.org/10.1016/j.amjcard.2007.09.119

[79] Xu, J., Song, Y.B., Hahn, J.Y., Chang, S.A., Lee, S.C., Choe, Y.H., Choi, S.H., Choi, J.H., Lee, S.H., Oh, J.K. and Gwon, H.C. (2012) Comparison of Magnetic Resonance Imaging Findings in Non-ST-Segment Elevation versus ST-Segment Elevation Myocardial Infarction Patients Undergoing Early Invasive Intervention. The International Journal of Cardiovascular Imaging, 28, 1487-1497. https://doi.org/10.1007/s10554-011-9975-2

[80] de Waha, S., Patel, M.R., Granger, C.B., Ohman, E.M., Maehara, A., Eitel, I., Ben-Yehuda, O., Jenkins, P., Thiele, H. and Stone, G.W. (2017) Relationship between Microvascular Obstruction and Adverse Events Following Primary Percutaneous Coronary Intervention for ST-Segment Elevation Myocardial Infarction: An Individual Patient Data Pooled Analysis from Seven Randomized Trials. European Heart Journal, 38, 3502-3510. https://doi.org/10.1093/eurheartj/ehx414

[81] Baks, T., van Geuns, R.J., Biagini, E., Wielopolski, P., Mollet, N.R., Cademartiri, F., van der Giessen, W.J., Krestin, G.P., Serruys, P.W., Duncker, D.J. and de Feyter, P.J. (2006) Effects of Primary Angioplasty for Acute Myocardial Infarction on Early and Late Infarct Size and Left Ventricular Wall Characteristics. Journal of the American College of Cardiology, 47, 40-44. https://doi.org/10.1016/j.jacc.2005.09.008

[82] Gerber, B.L., Rochitte, C.E., Melin, J.A., McVeigh, E.R., Bluemke, D.A., Wu, K.C., Becker, L.C. and Lima, J.A. (2000) Microvascular Obstruction and Left Ventricular 
Remodeling Early after Acute Myocardial Infarction. Circulation, 101, 2734-2741. https://doi.org/10.1161/01.CIR.101.23.2734

[83] Murry, C.E., Jennings, R.B. and Reimer, K.A. (1986) Preconditioning with Ischemia: A Delay of Lethal Cell Injury in Ischemic Myocardium. Circulation, 74, 1124-1136. https://doi.org/10.1161/01.CIR.74.5.1124

[84] Heusch, G. (2013) Cardioprotection: Chances and Challenges of Its Translation to the Clinic. The Lancet, 381, 166-175. https://doi.org/10.1016/S0140-6736(12)60916-7

[85] Hausenloy, D.J., Kharbanda, R., Rahbek Schmidt, M., Moller, U.K., Ravkilde, J., Okkels Jensen, L., Engstrom, T., Garcia Ruiz, J.M., Radovanovic, N., Christensen, E.F., et al. (2015) Effect of Remote Ischaemic Conditioning on Clinical Outcomes in Patients Presenting with an ST-Segment Elevation Myocardial Infarction Undergoing Primary Percutaneous Coronary Intervention. European Heart Journal, 36, 1846-1848.

[86] Pickard, J.M., Botker, H.E., Crimi, G., Davidson, B., Davidson, S.M., Dutka, D., Ferdinandy, P., Ganske, R., Garcia-Dorado, D., Giricz, Z., et al. (2015) Remote Ischemic Conditioning: From Experimental Observation to Clinical Application: Report from the 8th Biennial Hatter Cardiovascular Institute Workshop. Basic Research in Cardiology, 110, 453. https://doi.org/10.1007/s00395-014-0453-6

[87] Schmidt, M.R., Pryds, K. and Botker, H.E. (2014) Novel Adjunctive Treatments of Myocardial Infarction. World Journal of Cardiology, 6, 434-443. https://doi.org/10.4330/wjc.v6.i6.434

[88] Luo, S.J., Zhou, Y.J., Shi, D.M., Ge, H.L., Wang, J.L. and Liu, R.F. (2013) Remote Ischemic Preconditioning Reduces Myocardial Injury in Patients Undergoing Coronary Stent Implantation. Canadian Journal of Cardiology, 29, 1084-1089. https://doi.org/10.1016/j.cjca.2012.11.022

[89] Hausenloy, D.J., Mwamure, P.K., Venugopal, V., Harris, J., Barnard, M., Grundy, E., Ashley, E., Vichare, S., Di, S.C., Kolvekar, S., et al. (2007) Effect of Remote Ischaemic Preconditioning on Myocardial Injury in Patients Undergoing Coronary Artery Bypass Graft Surgery: A Randomised Controlled Trial. The Lancet, 370, 575-579. https://doi.org/10.1016/S0140-6736(07)61296-3

[90] Brevoord, D., Kranke, P., Kuijpers, M., Weber, N., Hollmann, M. and Preckel, B. (2012) Remote Ischemic Conditioning to Protect against Ischemia-Reperfusion Injury: A Systematic Review and Meta-Analysis. PLoS ONE, 7, e42179. https://doi.org/10.1371/journal.pone.0042179

[91] Zografos, T.A., Katritsis, G.D., Tsiafoutis, I., Bourboulis, N., Katsivas, A. and Katritsis, D.G. (2014) Effect of One-Cycle Remote Ischemic Preconditioning to Reduce Myocardial Injury during Percutaneous Coronary Intervention. American Journal of Cardiology, 113, 2013-2017. https://doi.org/10.1016/j.amjcard.2014.03.043

[92] Zografos, T.A., Katritsis, G.D. and Katritsis, D.G. (2014) Remote Ischemic Preconditioning Reduces Peri-Procedural Myocardial Injury in Elective Percutaneous Coronary Intervention: A Meta-Analysis. International Journal of Cardiology, 173, 530-532. https://doi.org/10.1016/j.ijcard.2014.03.026

[93] Rosenberg, J.H., Werner, J.H., Moulton, M.J. and Agrawal, D.K. (2018) Current Modalities and Mechanisms Underlying Cardioprotection by Ischemic Conditioning. Journal of Cardiovascular Translational Research, 11, 292-307. https://doi.org/10.1007/s12265-018-9813-1

[94] Manchurov, V., Ryazankina, N., Khmara, T., Skrypnik, D., Reztsov, R., Vasilieva, E. and Shpektor, A. (2014) Remote Ischemic Preconditioning and Endothelial Func- 
tion in Patients with Acute Myocardial Infarction and Primary PCI. The American Journal of Medicine, 127, 670-673. https://doi.org/10.1016/j.amjmed.2014.02.012

[95] Mewton, N., Thibault, H., Roubille, F., Lairez, O., Rioufol, G., Sportouch, C., Sanchez, I., Bergerot, C., Cung, T.T., Finet, G., et al. (2013) Postconditioning Attenuates No-Reflow in STEMI Patients. Basic Research in Cardiology, 108, 383. https://doi.org/10.1007/s00395-013-0383-8

[96] Mewton, N. and Ovize, M. (2013) Remote Preconditioning and All-Cause Mortality. The Lancet, 382, 579-580. https://doi.org/10.1016/S0140-6736(13)61607-4

[97] Le Page, S., Bejan-Angoulvant, T., Angoulvant, D. and Prunier, F. (2015) Remote Ischemic Conditioning and Cardioprotection: A Systematic Review and Meta-Analysis of Randomized Clinical Trials. Basic Research in Cardiology, 110, 11. https://doi.org/10.1007/s00395-015-0467-8

[98] McLeod, S.L., Iansavichene, A. and Cheskes, S. (2017) Remote Ischemic Perconditioning to Reduce Reperfusion Injury during Acute ST-Segment-Elevation Myocardial Infarction: A Systematic Review and Meta-Analysis. Journal of the American Heart Association, 6, pii: e005522. https://doi.org/10.1161/JAHA.117.005522

[99] Eitel, I., Stiermaier, T., Rommel, K.P., Fuernau, G., Sandri, M., Mangner, N., Linke, A., Erbs, S., Lurz, P., Boudriot, E., et al. (2015) Cardioprotection by Combined Intrahospital Remote Ischaemic Perconditioning and Postconditioning in ST-Elevation Myocardial Infarction: The Randomized LIPSIA CONDITIONING Trial. European Heart Journal, 36, 3049-3057. https://doi.org/10.1093/eurheartj/ehv463

[100] Okazaki, Y., Kodama, K., Sato, H., Kitakaze, M., Hirayama, A., Mishima, M., Hori, M. and Inoue, M. (1993) Attenuation of Increased Regional Myocardial Oxygen Consumption during Exercise as a Major Cause of Warm-Up Phenomenon. Journal of the American College of Cardiology, 21, 1597-1604.

https://doi.org/10.1016/0735-1097(93)90374-A

[101] Bogaty, P., Kingma, J.G., Guimond, J., Poirier, P., Boyer, L., Charbonneau, L. and Dagenais, G.R. (2001) Myocardial Perfusion Imaging Findings and the Role of Adenosine in the Warm-Up Angina Phenomenon. Journal of the American College of Cardiology, 37, 463-469. https://doi.org/10.1016/S0735-1097(00)01154-2

[102] Bulluck, H., Sirker, A., Loke, Y.K., Garcia-Dorado, D. and Hausenloy, D.J. (2016) Clinical Benefit of Adenosine as an Adjunct to Reperfusion in ST-Elevation Myocardial Infarction Patients: An Updated Meta-Analysis of Randomized Controlled Trials. International Journal of Cardiology, 202, 228-237. https://doi.org/10.1016/j.ijcard.2015.09.005

[103] Singh, M., Shah, T., Khosla, K., Singh, P., Molnar, J., Khosla, S. and Arora, R. (2012) Safety and Efficacy of Intracoronary Adenosine Administration in Patients with Acute Myocardial Infarction Undergoing Primary Percutaneous Coronary Intervention: A Meta-Analysis of Randomized Controlled Trials. Therapeutic Advances in Cardiovascular Disease, 6, 101-114. https://doi.org/10.1177/1753944712446670

[104] Navarese, E.P., Buffon, A., Andreotti, F., Gurbel, P.A., Kozinski, M., Kubica, A., Musumeci, G., Cremonesi, A., Tavazzi, L., Kubica, J. and Castriota, F. (2012) Adenosine Improves Post-Procedural Coronary Flow But Not Clinical Outcomes in Patients with Acute Coronary Syndrome: A Meta-Analysis of Randomized Trials. Atherosclerosis, 222, 1-7. https://doi.org/10.1016/j.atherosclerosis.2011.11.001

[105] Ross, A.M., Gibbons, R.J., Stone, G.W., Kloner, R.A., Alexander, R.W. and Investigators, A.-I. (2005) A Randomized, Double-Blinded, Placebo-Controlled Multicenter Trial of Adenosine as an Adjunct to Reperfusion in the Treatment of Acute 
myocardial Infarction (AMISTAD-II). Journal of the American College of Cardiology, 45, 1775-1780. https://doi.org/10.1016/j.jacc.2005.02.061

[106] Mahaffey, K.W., Puma, J.A., Barbagelata, N.A., DiCarli, M.F., Leesar, M.A., Browne, K.F., Eisenberg, P.R., Bolli, R., Casas, A.C., Molina-Viamonte, V., et al. (1999) Adenosine as an Adjunct to Thrombolytic Therapy for Acute Myocardial Infarction: Results of a Multicenter, Randomized, Placebo-Controlled Trial: The Acute Myocardial Infarction Study of Adenosine (AMISTAD) Trial. Journal of the American College of Cardiology, 34, 1711-1720. https://doi.org/10.1016/S0735-1097(99)00418-0

[107] Berne, R.M. (1980) The Role of Adenosine in the Regulation of Coronary Blood Flow. Circulation Research, 47, 807-813. https://doi.org/10.1161/01.RES.47.6.807

[108] Olafsson, B., Forman, M.B., Puett, D.W., Pou, A., Cates, C.U., Friesinger, G.C. and Virmani, R. (1987) Reduction of Reperfusion Injury in the Canine Preparation by Intracoronary Adenosine: Importance of the Endothelium and the "No-Reflow" Phenomenon. Circulation, 76, 1135-1145. https://doi.org/10.1161/01.CIR.76.5.1135

[109] Marzilli, M., Orsini, E., Marraccini, P. and Testa, R. (2000) Beneficial Effects of Intracoronary Adenosine as an Adjunct to Primary Angioplasty in Acute Myocardial Infarction. Circulation, 101, 2154-2159. https://doi.org/10.1161/01.CIR.101.18.2154

[110] Goto, M., Miura, T., Iliodoromitis, E.K., O’Leary, E.L., Ishimoto, R., Yellon, D.M. and Iimura, O. (1991) Adenosine Infusion during Early Reperfusion Failed to Limit Myocardial Infarct Size in a Collateral Deficient Species. Cardiovascular Research, 25, 943-949. https://doi.org/10.1093/cvr/25.11.943

[111] Nazir, S.A., Khan, J.N., Mahmoud, I.Z., Greenwood, J.P., Blackman, D.J., Kunadian, V., Been, M., Abrams, K.R., Wilcox, R., Adgey, A.A.J., et al. (2016) The REFLO-STEMI (Reperfusion Facilitated by Local Adjunctive Therapy in ST-Elevation Myocardial Infarction) Trial: A Randomised Controlled Trial Comparing Intracoronary Administration of Adenosine or Sodium Nitroprusside with Control for Attenuation of Microvascular Obstruction during Primary Percutaneous Coronary Intervention.

[112] Nazir, S.A., Khan, J.N., Mahmoud, I.Z., Greenwood, J.P., Blackman, D.J., Kunadian, V., Been, M., Abrams, K.R., Wilcox, R., Adgey, A.A., et al. (2014) The REFLO-STEMI Trial Comparing Intracoronary Adenosine, Sodium Nitroprusside and Standard Therapy for the Attenuation of Infarct Size and Microvascular Obstruction during Primary Percutaneous Coronary Intervention: Study Protocol for a Randomised Controlled Trial. Trials, 15, 371.

https://doi.org/10.1186/1745-6215-15-371

[113] Zhou, S.S., Tian, F., Chen, Y.D., Wang, J., Sun, Z.J., Guo, J. and Jin, Q.H. (2015) Combination Therapy Reduces the Incidence of No-Reflow after Primary Percutaneous Coronary Intervention in Patients with ST-Segment Elevation Acute Myocardial Infarction. Journal of Geriatric Cardiology, 12, 135-142. https://doi:10.11909/j.issn.1671-5411.2015.02.003

[114] Prunier, F., Angoulvant, D., Saint Etienne, C., Vermes, E., Gilard, M., Piot, C., Roubille, F., Elbaz, M., Ovize, M., Biere, L., et al. (2014) The RIPOST-MI Study, Assessing Remote Ischemic Perconditioning alone or in Combination with Local Ischemic Postconditioning in ST-Segment Elevation Myocardial Infarction. Basic Research in Cardiology, 109, 400. https://doi.org/10.1007/s00395-013-0400-y

[115] Alburquerque-Bejar, J.J., Barba, I., Inserte, J., Miro-Casas, E., Ruiz-Meana, M., Poncelas, M., Vilardosa, U., Valls-Lacalle, L., Rodriguez-Sinovas, A. and Garcia-Dorado, D. (2015) Combination Therapy with Remote Ischaemic Conditioning 
and Insulin or Exenatide Enhances Infarct Size Limitation in Pigs. Cardiovascular Research, 107, 246-254. https://doi.org/10.1093/cvr/cvv171

[116] Kunichika, H., Ben-Yehuda, O., Lafitte, S., Kunichika, N., Peters, B. and DeMaria, A.N. (2004) Effects of Glycoprotein IIb/IIIa Inhibition on Microvascular Flow after Coronary Reperfusion. A Quantitative Myocardial Contrast Echocardiography Study. Journal of the American College of Cardiology, 43, 276-283. https://doi.org/10.1016/j.jacc.2003.08.040

[117] Montalescot, G., Barragan, P., Wittenberg, O., Ecollan, P., Elhadad, S., Villain, P., Boulenc, J.M., Morice, M.C., Maillard, L., Pansieri, M., et al. (2001) Platelet Glycoprotein IIb/IIIa Inhibition with Coronary Stenting for Acute Myocardial Infarction. The New England Journal of Medicine, 344, 1895-1903. https://doi.org/10.1056/NEJM200106213442503

[118] Ito, H., Taniyama, Y., Iwakura, K., Nishikawa, N., Masuyama, T., Kuzuya, T., Hori, M., Higashino, Y., Fujii, K. and Minamino, T. (1999) Intravenous Nicorandil Can Preserve Microvascular Integrity and Myocardial Viability in Patients with Reperfused Anterior Wall Myocardial Infarction. Journal of the American College of Cardiology, 33, 654-660. https://doi.org/10.1016/S0735-1097(98)00604-4

[119] Jia, X.W., Fu, X.H., Zhang, J., Gu, X.S., Fan, W.Z., Wu, W.L., Hao, G.Z., Li, S.Q. and Jiang, Y.F. (2009) Intensive Cholesterol Lowering with Statin Improves the Outcomes of Percutaneous Coronary Intervention in Patients with Acute Coronary Syndrome. Chinese Medical Journal, 122, 659-664.

[120] Woo, J.S., Kim, W., Ha, S.J., Kim, J.B., Kim, S.J., Kim, W.S., Seon, H.J. and Kim, K.S. (2013) Cardioprotective Effects of Exenatide in Patients with ST-Segment-Elevation Myocardial Infarction Undergoing Primary Percutaneous Coronary Intervention: Results of Exenatide Myocardial Protection in Revascularization Study. Arteriosclerosis, Thrombosis, and Vascular Biology, 33, 2252-2260. https://doi.org/10.1161/ATVBAHA.113.301586

[121] Chen, W.R., Shen, X.Q., Zhang, Y., Chen, Y.D., Hu, S.Y., Qian, G., Wang, J., Yang, J.J., Wang, Z.F. and Tian, F. (2016) Effects of Liraglutide on Left Ventricular Function in Patients with Non-ST-Segment Elevation Myocardial Infarction. Endocrine, 52, 516-526. https://doi.org/10.1007/s12020-015-0798-0

[122] Campo, G., Pavasini, R., Morciano, G., Lincoff, A.M., Gibson, C.M., Kitakaze, M., Lonborg, J., Ahluwalia, A., Ishii, H., Frenneaux, M., et al. (2017) Clinical Benefit of Drugs Targeting Mitochondrial Function as an Adjunct to Reperfusion in ST-Segment Elevation Myocardial Infarction: A Meta-Analysis of Randomized Clinical Trials. International Journal of Cardiology, 244, 59-66. https://doi.org/10.1016/j.ijcard.2017.06.040

[123] Grimaldi-Bensouda, L., Rossignol, M., Danchin, N., Steg, P.G., Bessede, G., Ovize, M., Cottin, Y., Autret-Leca, E., Benichou, J., Abenhaim, L. and Group PG-MIS (2011) Risk of ST versus Non-ST Elevation Myocardial Infarction Associated with Non-Steroidal Anti-Inflammatory Drugs. Heart, 97, 1834-1840. https://doi.org/10.1136/hrt.2011.222448

[124] Hippisley-Cox, J. and Coupland, C. (2005) Risk of Myocardial Infarction in Patients Taking Cyclo-Oxygenase-2 Inhibitors or Conventional Non-Steroidal Anti-Inflammatory Drugs: Population Based Nested Case-Control Analysis. BMJ, 330, 1366. https://doi.org/10.1136/bmj.330.7504.1366

[125] Johnsen, S.P., Larsson, H., Tarone, R.E., McLaughlin, J.K., Norgard, B., Friis, S. and Sorensen, H.T. (2005) Risk of Hospitalization for Myocardial Infarction among Users of Rofecoxib, Celecoxib, and Other NSAIDs: A Population-Based Case-Control Study. Archives of Internal Medicine, 165, 978-984. 
https://doi.org/10.1001/archinte.165.9.978

[126] Cannon, C.P., Husted, S., Harrington, R.A., Scirica, B.M., Emanuelsson, H., Peters, G., Storey, R.F. and Investigators, D. (2007) Safety, Tolerability, and Initial Efficacy of AZD6140, the First Reversible Oral Adenosine Diphosphate Receptor Antagonist, Compared with Clopidogrel, in Patients with Non-ST-Segment Elevation Acute Coronary Syndrome: Primary Results of the DISPERSE-2 Trial. Journal of the American College of Cardiology, 50, 1844-1851.

https://doi.org/10.1016/j.jacc.2007.07.053

[127] Gurbel, P.A., Bliden, K.P., Butler, K., Tantry, U.S., Gesheff, T., Wei, C., Teng, R., Antonino, M.J., Patil, S.B., Karunakaran, A., et al. (2009) Randomized Double-Blind Assessment of the ONSET and OFFSET of the Antiplatelet Effects of Ticagrelor versus Clopidogrel in Patients with Stable Coronary Artery Disease: The ONSET/OFFSET Study. Circulation, 120, 2577-2585.

https://doi.org/10.1161/CIRCULATIONAHA.109.912550

[128] Storey, R.F., Angiolillo, D.J., Patil, S.B., Desai, B., Ecob, R., Husted, S., Emanuelsson, H., Cannon, C.P., Becker, R.C. and Wallentin, L. (2010) Inhibitory Effects of Ticagrelor Compared with Clopidogrel on Platelet Function in Patients with Acute Coronary Syndromes: The PLATO (PLATelet Inhibition and Patient Outcomes) PLATELET Substudy. Journal of the American College of Cardiology, 56, 1456-1462. https://doi.org/10.1016/j.jacc.2010.03.100

[129] Sherwood, M.W., Wiviott, S.D., Peng, S.A., Roe, M.T., Delemos, J., Peterson, E.D. and Wang, T.Y. (2014) Early Clopidogrel versus Prasugrel Use among Contemporary STEMI and NSTEMI Patients in the US: Insights from the National Cardiovascular Data Registry. Journal of the American Heart Association, 3, e000849. https://doi.org/10.1161/JAHA.114.000849

[130] Yang, A., Pon, Q., Lavoie, A., Crawford, J.J., Harenberg, S., Zimmermann, R.H., Booker, J., Kelly, S., Lavi, S., Cantor, W.J., et al. (2018) Long-Term Pharmacodynamic Effects of Ticagrelor versus Clopidogrel in Fibrinolytic-Treated STEMI Patients Undergoing Early PCI. Journal of Thrombosis and Thrombolysis, 45, 225-233. https://doi.org/10.1007/s11239-017-1581-2

[131] Martinez-Rios, M.A., Rosas, M., Gonzalez, H., Pena-Duque, M.A., Martinez-Sanchez, C., Gaspar, J., Garcia, H., Gaxiola, E., Delgado, L., Carrillo, J., et al. (2004) Comparison of Reperfusion Regimens with or without Tirofiban in ST-Elevation Acute Myocardial Infarction. American Journal of Cardiology, 93, 280-287. https://doi.org/10.1016/j.amjcard.2003.10.005 